\title{
Pemanfaatan Pantulan Bola Karet sebagai Pemanen Energi pada Piezoelektrik
}

\author{
Ade Sunard*, Adhes Gamayel \\ Program Studi Teknik Mesin, Sekolah Tinggi Teknologi Jakarta \\ Jl. Jatiwaringin Raya No.278 Pondok Gede \\ *E-mail: ade@sttj.ac.id
}

\begin{abstract}
Abstrak - Piezoelektrik adalah salah satu pemanen energi yang mampu mengubah energi mekanis dari getaran menjadi energi listrik. Piezoelektrik menjadi sumber energi yang menarik karena ramah lingkungan dan hanya membutuhkan tekanan berulang untuk menghasilkan listrik. Di sisi lain, bola karet adalah bola yang dapat melakukan gerakan pantulan secara berulang. Oleh karena itu, perlu dilakukan penelitian lebih jauh tentang potensi panen energi pada bola karet dengan memanfaatkan piezoelektrik. Metode penelitian yang dilakukan adalah mengetahui nilai tegangan listrik dari pengujian jatuhnya bola karet pada ketinggian 15,20, $25 \mathrm{~cm}$ tepat diatas piezoelektrik berukuran 120 x $50 \mathrm{~mm}$. Hasil penelitian didapatkan bahwa dua bola karet yang dijatuhkan pada ketinggian $25 \mathrm{~cm}$ memiliki nilai tegangan listrik tertinggi yaitu 7,712 volt. Ketinggian awal bola karet berpengaruh terhadap energi mekanik yang dihasillkan. Semakin tinggi bola karet, kecepatan saat menumbuk piezoelektrik semakin cepat, sehingga lendutan pada piezoelektrik menjadi besar dan menghasilkan tegangan listrik..
\end{abstract}

Kata kunci : piezoelektrik, bola karet, tumbukan, lendutan

\section{Pendahuluan}

Pemanen energi adalah alat untuk mengumpulkan energi dari energi mekanis dan dikonversikan menjadi energi listrik. Energi listrik yang dihasilkan pada alat pemanen energi relatif kecil sehingga tidak bisa langsung dimanfaatkan [1]. Umumnya energi yang dihasilkan disimpan terlebih dahulu dalam penyimpan energi listrik seperti baterai atau konduktor. Salah satu pemanen energi yang mengkonversikan getaran menjadi energi listrik adalah piezoelektrik [2]. Piezoelektrik menjadi sumber energi yang menarik karena ramah lingkungan dan membutuhkan tekanan yang berulang untuk menghasilkan listrik. Namun, tegangan listrik yang dihasilkan kecil dan harga material mahal masih menjadi kelemahan dari piezoelektrik.

Di Indonesia telah dilakukan penelitian mengenai pemanfaatan piezoelektrik sebagai sumber energi listrik terbarukan seperti pemanfaatan piezoelektrik pada Rail Base untuk menjadi sumber energi pada palang pintu rel kereta api [3], air hujan [4], sepatu [5], dan polisi tidur [6]. Tekanan menjadi faktor yang berpengaruh terhadap kinerja piezoelektrik. Saat air hujan turun dengan tekanan tinggi mampu menghasilkan 0.72 DC volt [4]. Sepatu yang dipasang piezoelektrik dan diuji pada orang dengan berat 55, 60, dan $65 \mathrm{~kg}$ menghasilkan voltase tertinggi 1,16 volt pada berat $65 \mathrm{~kg}$ [5]. Mobil diuji pada prototype polisi tidur dan melewati sebanyak 60 kali sehingga menghasilkan energi listrik sebesar $380 \mathrm{mV}$ selama 1200 detik [6]. Berdasarkan penelitian diatas, perlu diadakan penelitian dan studi tentang panen energi menggunakan peralatan sederhana dan ada di lingkungan sekitar. Peralatan yang digunakan harus mampu menimbulkan gerak secara berulang agar piezoelektrik yang dipasang dapat menghasilkan energi listrik secara terus menerus. Tujuan dari penelitian ini untuk mengetahui adanya potensi gerakan berulang yang dilakukan oleh bola karet. Selain itu, diharapkan dengan adanya penelitian ini mampu menghasilkan ide baru untuk aplikasi panen energi pada alat-alat yang ada disekitar manusia.

\section{Dasar Teori}

\subsection{Piezoelektrik}

Piezoelektrik adalah suatu material penghasil tegangan listrik bila mendapatkan tekanan. Saat mengalami tekanan, terjadi perubahan pergerakan elektron dari acak menjadi searah dan terpolarisasi sehingga terbentuk muatan positif dan negatif. Semakin besar tekanan yang terjadi, maka proses polarisasi lebih cepat dan besarnya perbedaan antara muatan positif dan negatif menyebabkan nilai tegangan listrik besar.
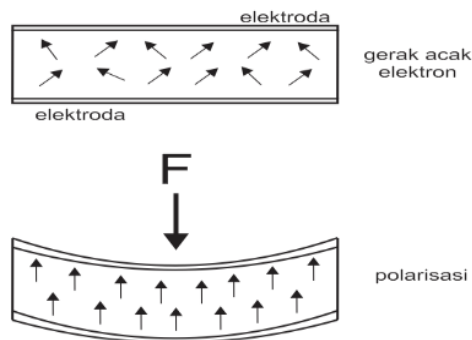

Gambar 1. Piezoelektrik saat mengalami gaya tekan 


\subsection{Bola karet, Energi Mekanik dan Momentum}

Bola karet adalah bola berbahan karet dengan tingkat elastisitas tertentu sehingga dapat memantul kembali. Bola karet dapat dimanfaatkan untuk latihan olahraga seperti peningkatan keahlian heading dalam sepak bola [7], dan latihan operan dalam bola voli [8]. Namun ada satu bola karet padat yang sering dipakai pada permainan tradisional yaitu bola bekel. Bola bekel memiliki kepadatan bahan karet sehingga saat dijatuhkan ke atas tanah akan memantul lagi hingga diam.

Bola karet yang dijatuhkan dari atas tanah memiliki energi mekanik dengan perubahan dari energi potensial menjadi energi kinetik. Energi potensial dipengaruhi oleh massa (m) dan ketinggian (h) dengan persamaan [9]

$$
E P=m \cdot g \cdot h
$$

Dimana :

$$
\begin{aligned}
& \mathrm{EP}=\text { Energi Potensial }(\text { Joule) } \\
& \mathrm{m}=\text { Massa }(\mathrm{kg}) \\
& \mathrm{g} \quad \text { percepatan gravitasi }\left(\mathrm{m} / \mathrm{s}^{2}\right) \\
& \mathrm{h}
\end{aligned}
$$

Energi kinetik dipengaruhi oleh massa (m) dan kecepatan (v). adapun persamaan energi kinetik adalah [9]:

$$
E K=\frac{1}{2} \cdot m \cdot v^{2}
$$

Dimana :

$$
\begin{aligned}
& \mathrm{EK}=\text { Energi Kinetik (Joule) } \\
& \mathrm{m}=\operatorname{Massa}(\mathrm{kg}) \\
& \mathrm{v} \quad=\operatorname{kecepatan}(\mathrm{m} / \mathrm{s})
\end{aligned}
$$

Dari kedua persamaan tersebut, dapat diketahui kecepatan benda jatuh sesaat menyentuh tanah yaitu [9] :

$$
\begin{gathered}
E M_{1}=E M_{2} \\
E P_{1}+E K_{1}=E P_{2}+E K_{2}
\end{gathered}
$$

Pada kondisi sebelum benda jatuh, kecepatannya adalah nol, sehingga tidak ada energi kinetik $\left(\mathrm{EK}_{1}=0\right)$.

Pada kondisi benda tepat menyentuh tanah, maka nilai ketinggian adalah nol, sehingga tidak ada energi potensial $\left(\mathrm{EP}_{2}=0\right)$

Dari kedua kondisi ini, maka kecepatan sesaat sebelum menyentuh tanah adalah

$$
\begin{gathered}
E P_{1}=E K_{2} \\
m \cdot g \cdot h_{1}=\frac{1}{2} m \cdot v^{2} \\
\sqrt{2 \cdot g \cdot h_{1}}=v
\end{gathered}
$$

Dari persamaan ini dapat disimpulkan bahwa kecepatan sesaat benda sebelum menyentuh tanah tergantung dari ketinggian yang dimilikinya. Semakin tinggi suatu benda dijatuhkan, maka semakin tinggi kecepatan yang dihasilkan.

Gerakan bola karet ini termasuk dalam elastis sebagian dan memiliki hubungan dengan hukum momentum. Momentum adalah kecenderungan benda yang bergerak untuk melanjutkan gerakannya pada kelajuan yang konstan. Momentum merupakan besaran vektor yang searah dengan kecepatan benda. Secara matematis dituliskan [9]

$$
P=m \cdot v
$$

Dimana

$$
\begin{aligned}
\mathrm{P} & =\operatorname{Momentum}(\mathrm{kg} \cdot \mathrm{m} / \mathrm{s}) \\
\mathrm{m} & =\operatorname{Massa}(\mathrm{kg}) \\
\mathrm{v} & =\operatorname{kecepatan}(\mathrm{m} / \mathrm{s})
\end{aligned}
$$

Koefisien restitusi (e) adalah tingkat kelentingan suatu tumbukan yang dapat dinyatakan sebagai sebuah nilai. Besarnya koefisien restitusi untuk pantulan bola [9]

$$
e=\sqrt{\frac{h_{2}}{h_{1}}}=\sqrt{\frac{h_{1}}{h}}
$$

Dimana :

$\mathrm{e}=$ koefisien restitusi

$\mathrm{h}=$ tinggi bola mula-mula

$\mathrm{h}_{1}=$ tinggi pantulan ke- 1

$\mathrm{h}_{2}=$ tinggi pantulan ke-2

\section{Metodologi Penelitian}

\subsection{Metode Penelitian}

Penelitian yang dilakukan adalah penelitian eksperimental sungguhan (true experimental research) dengan mengukur tegangan listrik yang dihasilkan oleh piezoelektrik ketika bola karet sebanyak 1 (satu) dan 2 (dua) bola dijatuhkan pada ketinggian 15, 20, dan $25 \mathrm{~cm}$.

3.2. Alat, Bahan dan Instalasi Penelitian

Piezoelektrik yang digunakan berbahan keramik berukuran 120 x $50 \mathrm{~mm}$ dan tebal $0.5 \mathrm{~mm}$. Ujung piezoelektrik dijepit sepanjang $10 \mathrm{~mm}$ di kedua sisinya. Bola karet yang digunakan adalah bola bekel dengan diameter $30.7 \mathrm{~mm}$ dan berat 170 gram.

Pengukuran tegangan listrik pada piezoelektrik yang bertumbukan dengan bola karet menggunakan DAQ Instrument dengan pengambilan sebanyak 25 data tiap 1 detik kemudian di konversikan kedalam tabel excel. Skema penelitian dapat dilihat pada gambar 2 


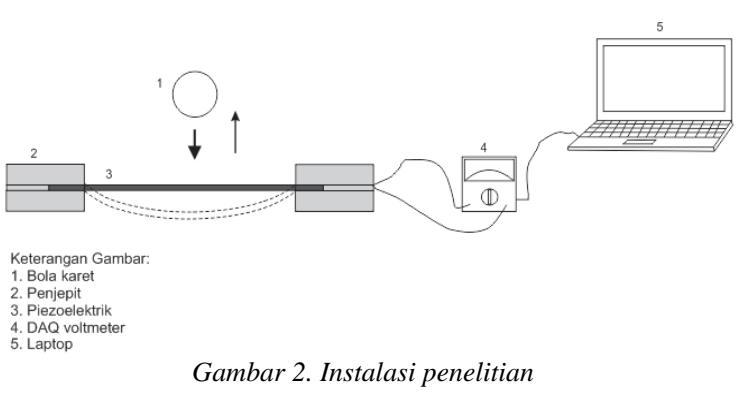

\section{Temuan dan Pembahasan}

\subsection{Hubungan ketinggian dan voltase}

Pada ketinggian $25 \mathrm{~cm}$, voltase yang dihasilkan adalah voltase tertinggi, dimana tegangan listrik yang dihasilkan oleh satu bola sebesar 5.921 volt dan dua bola sebesar 7.712 volt. Ketinggian bola karet saat dijatuhkan memiliki pengaruh terhadap voltase yang dihasilkan oleh piezoelektrik. Hal ini terjadi karena saat bola dijatuhkan pada ketinggian tertentu, maka energi mekanik akan menumbuk piezoelektrik hingga penampang piezoelektrik melendut ke arah bawah. Energi mekanik terdiri dari energi potensial dan energi kinetik yang dipengaruhi oleh ketinggian suatu benda dan kecepatan benda jatuh. Semakin tinggi letak bola karet untuk dijatuhkan, semakin besar kecepatan bola karet saat menumbuk piezoelektrik, maka semakin besar lendutan yang terjadi pada penampang piezoelektrik sehingga tegangan listrik yang dihasilkan semakin tinggi. Hubungan ketinggian dan voltase ditampilkan pada gambar 3

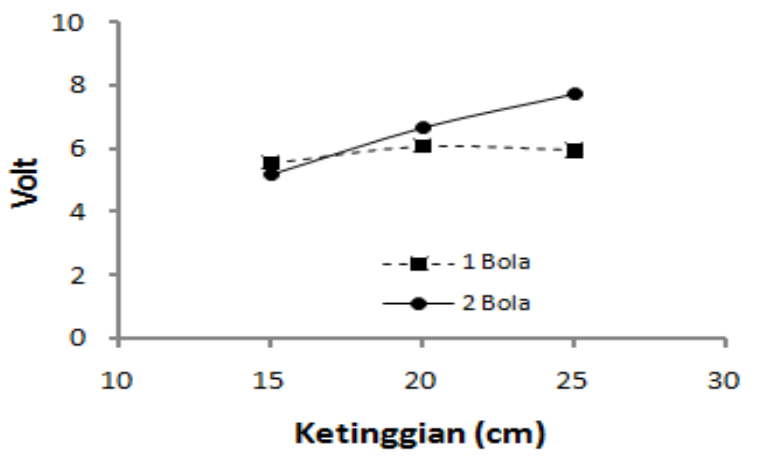

Gambar 3. Hubungan ketinggian dan voltase

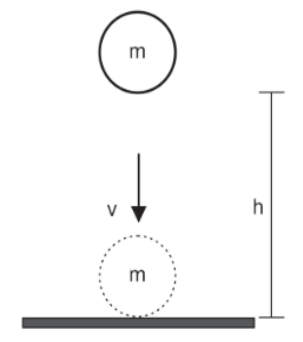

(a)

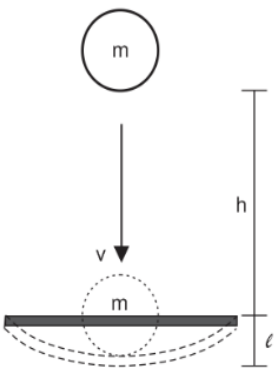

(b)
Gambar 4. Ilustrasi perubahan (a) energi potensial menjadi energi kinetik (b) terjadi momentum dan mengakibatkan lendutan pada piezoelektrik
4.2. Hubungan momentum dan ketinggian

Dua buah bola karet yang dijatuhkan secara bersama-sama memiliki nilai voltase paling tinggi dibandingkan dengan satu buah bola karet yang dijatuhkan. Hal ini dipengaruhi oleh nilai massa yang dimiliki dua bola karet lebih tinggi nilainya daripada nilai massa satu buah bola karet, sehingga momentum tumbukan yang dimiliki 2 bola karet lebih besar saat menumbuk piezoelektrik. Momentum tumbukan adalah perkalian antara massa dan kecepatan. Momentum tumbukan besar menyebabkan permukaan piezoelektrik melendut dan menghasilkan voltase tinggi. Ilustrasi perubahan energi potensial menjadi energi kinetik hingga terjadi momentum dan mengakibatkan lendutan pada piezoelektrik ditampilkan pada gambar 4. Hubungan ketinggian dan momentum dapat dilihat pada gambar 5 .

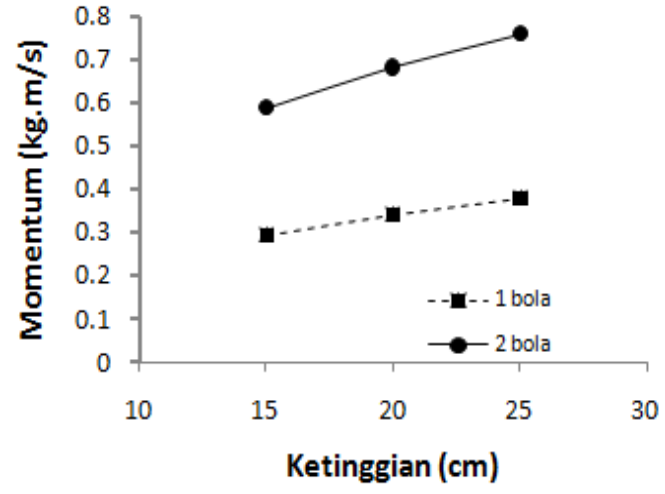

Gambar 5. Hubungan ketinggian dan momentum

\section{Simpulan dan saran}

\subsection{Simpulan}

Simpulan yang dapat diambil dari pembahasan diatas adalah

1. Ketinggian bola karet sesaat sebelum jatuh meningkatkan tegangan listrik yang dihasilkan oleh piezoelektrik. Pada percobaan ini, ketinggian $25 \mathrm{~cm}$ menghasilkan voltase tertinggi

2. Massa bola karet berpengaruh terhadap tegangan listrik yang dihasilkan oleh piezoelektrik. Pada penelitian ini, dua bola karet yang dijatuhkan bersamaan menghasilkan voltase lebih tinggi dibandingkan satu bola karet

\subsection{Saran}

Beberapa saran yang bisa dilakukan untuk penelitian lebih lanjut antara lain

1. Perlu studi lebih lanjut mengenai pola pantulan/lentingan bola karet saat menumbuk piezoelektrik

2. Perlu adanya tampilan grafik osilasi dari setiap tumbukan yang dihasilkan agar lebih terlihat fenomena yang terjadi pada piezoelektrik. 


\section{Kepustakaan}

[1] Gamayel A. Pengaruh Bentuk Bluff Body Terhadap Tegangan Listrik yang Dihasilkan Piezoelektrik dengan Sistem Kantilever. In Prosiding Seminar Nasional Teknoka; 2017; Jakarta. p. E1-E5.

[2] Kokkinopoulos A, Vokas G, Papageorgas P. Energy harvesting implementing embedded piezoelectric generators - The potential for the Attiki Odos traffic grid. In The International Conference on Technologies and Materials for Renewable Energy, Environment and Sustainability, TMREES14; 2014. p. 1070 - 1085.

[3] Pradipta IMD, Ekasar A, Gunawan R. Panen Energi Listrik dari Rail Base dengan Memanfaatkan Piezoelektrik. PKM-GT. 2012.

[4] Almanda D, Dermawan E, Diniardi E, Syawaluddin S, Ramadhan AI. Pengujian Desain Model Piezoelektrik PVDF Berdasarkan Variasi Tekanan. In Seminar Nasional Sains dan Teknologi Fakultas Teknik Universitas Muhammadiyah Jakarta; 2016; Jakarta. p. 1-6.

[5] Maulana R. Pemanfaatan Sensor Piezoelektrik sebagai Penghasil Sumber Energi pada Sepatu. Skripsi. Surakarta: Universitas Muhammadiyah Surakarta, Program Studi Teknik Elektro; 2016.

[6] Yulia E, Putra EP, Ekawati ,E, N. Polisi Tidur Piezoelektrik Sebagai Pembangkit Listrik dengan Memanfaatkan Energi Mekanik Kendaraan Bermotor. Jurnal Otomasi, Kontrol, dan Instrumentasi. 2016; 8(1).

[7] Muluri. Meningkatkan Heading dengan Bola Karet dalam Permainan Sepak Bola di SDN 14 Sungai Putat. Artikel Ilmiah. Pontianak: Universitas Tanjungpura, Ilmu Keolahragaan; 2017.

[8] Setiana I, Simanjuntak V, Supriatna E. Pendekatan Media Bola Karet Passing Bawah Bola Voli Kelas IV SDN 01 Singkawang Tengah. Jurnal Pendidikan dan Pembelajaran. 2014; 3(9).

[9] Young HD, Freedman RA, Juliastuti E. Fisika Unversitas. Kesepuluh ed. Wibi H, Simarmata L, Safitri A, editors. Jakarta: Erlangga; 2002. 